\title{
Valorization of Food Loss and Wastes: Feedstocks for Biofuels and Valuable Chemicals
}

\author{
Shehu Isah ${ }^{1}$ and Gulnihal Ozbay ${ }^{2 *}$ \\ ${ }^{1}$ Department of Chemistry, Delaware State University, Dover, DE, United States, ${ }^{2}$ Department of Agriculture and Natural \\ Resources, Delaware State University, Dover, DE, United States
}

Reduction in the amount of food loss and waste requires appropriate quantification method of the amount of food loss annually on the one hand and devising alternative use for foods that would otherwise end up as loss or waste. In this review, food loss and waste (FLW) were classified as avoidable, non-avoidable and possibly avoidable wastes based on inherent composition of several food categories. The current disposal methods of FLW were evaluated for its effectiveness and overall environmental impacts presented by landfills, composting and incineration. Alternative and sustainable alternative for management of food loss and waste include feedstocks for biofuel production,

OPEN ACCESS

Edited by:

Christian John Reynolds,

City University of London,

United Kingdom

Reviewed by:

Antoni Sánchez,

Autonomous University of Barcelona, Spain Keat Teong Lee,

University of Science Malaysia, Malaysia

*Correspondence: Gulnihal Ozbay gozbay@desu.edu

Specialty section:

This article was submitted to

Nutrition and Sustainable Diets,

a section of the journal

Frontiers in Sustainable Food Systems

Received: 06 June 2019

Accepted: 05 May 2020

Published: 17 June 2020

Citation:

Isah S and Ozbay G (2020) Valorization of Food Loss and Wastes:

Feedstocks for Biofuels and Valuable

Chemicals.

Front. Sustain. Food Syst. 4:82.

doi: 10.3389/fsufs.2020.00082 valuable chemicals and coproducts. This approach is renewable, environmentally friendly, improved social status through job creation for local communities and overall improved quality of life.

Keywords: AW, avoidable waste, nonavoidable waste, sustainability, food loss, feedstocks for bio fuel, conversion to valuable chemicals

\section{INTRODUCTION}

A comprehensive evaluation of the quantity or value of food waste or loss is necessary in devising effective strategies for avoiding and/or minimizing such loss. Such measures are aimed at managing the supply and demand in food chain. This is becoming more imperative from the rapidly growing global population which in turn, is demanding more resources to guarantee food security. A delicate balance on increased food production and overall minimal impact on the environment must be established for sustainable development. Sequel to this challenge the United Nations in 2015 (Target 12.3) adopted specified certain objectives in its "Sustainable Development Goals (SDG)" to reduce food loss and waste around the world to "half per capital at both the consumer and distribution points and consequently, food losses along the production chain by 2030." Accomplishing these targets require proper quantification of losses from supply end including production, retail and consumer levels. However, several research and growing body of literature available today differ on common definitional framework and methodological approaches for quantifying FLW (De Laurentiis et al., 2018; Corrado et al., 2019).

Interestingly however, the waste management of food under the auspice of Food and Agricultural Organization (FAO) is actively leading in setting the definitional framework of FLW. It refers to food loss as, "food produced for human consumption but not eaten by human." It went further to define food loss as "the decrease in the amount or value of food," while food waste is considered as a component of food loss which is referred to as "the disposal or non-food use of food that was intended for consumption along the entire food production and distribution chain, that is, from production to consumer l." On the other hand, food waste is a unique and separate 
part of food loss because the causes of food waste and its preventive strategies are different from those of food losses (FAO, 2013).

The quantity of food loss and waste globally was put "at 33\% of food intended for consumption" (FAO, 2011). This was further broken down per regions around the world and per capital food waste at consumer level as $98-115 \mathrm{~kg} /$ year in the NorthAmerica and Europe and " $6-11 \mathrm{~kg} /$ year in sub-Sahara Africa and South/Southeast Asia" (FAO, 2011). In another research carried out by De Laurentiis et al. (2018), which evaluated food loss and waste attributable to production up to final consumption stage, it was determined that nearly " $180 \mathrm{~kg}$ per person per annum of food is wasted yearly in the Europe alone" Isah et al., 2019. A great proportion of this loss is attributed to consumer level: "a little over a $100 \mathrm{~kg}$ per person per annum is generated at the consumer level of which $76 \mathrm{~kg}$ is attributed to individual homes and $25 \mathrm{~kg}$ for restaurants and food industry." Thus, consumptions at individual homes are highly implicated in food loss and waste. In China, "organic waste" was highly implicated and narrowed to the consumption of vegetables, nuts and fresh fruits. The implication of this findings is that industrialization and accruing improvement in standard of life may lead to increasing consumption of fruit and vegetable, and thus, "high ratio of organic waste." Similar pattern was observed in Australia with respect to fruits and vegetables where it was implicated as one of the reasons for food loss and waste as high as 286 tons per annum (Zhang et al., 2010; Ghosh et al., 2017). Significant amount of food loss and waste occur at the distribution and point of human consumption.

\section{Measure and Classification of Food Wastes}

There is no globally agreed definition of FLW. Most existing quantifications of FLW have varying system boundaries which account for different reported values of FLW across the supply chain. Poorly defined system boundaries in the literature is one major limitation in classification of FLW. The previous research work of Gustavsson et al. (2011), food loss with respect to animal captured "losses rearing stage in the definition of system boundary." In similar work of Barrett et al. (2013), Stenmarck et al. (2016) food loss exclude those losses and the system boundary begins from the point of slaughter of animal. Measure of FLW from production conducted by Hartikainen et al. (2018) defined system boundary as including all agricultural activities (crop production aquaculture and fishing), starting from plants harvest, hatching of fish, animals birth, milk production and when eggs are laid. Boundary system terminates at the point of processing or market distribution.

This lack of uniformity in system boundaries have led to different definitional framework and thus, different values of FLW. The definitional framework of "Food Use For Social Innovation by Optimizing Waste Prevention Strategies" (FUSIONS) focused on the value of food waste recorded within each country European union. On the other hand, the "FLW Accounting and Reporting Standards" (FLW Standard) enables a "different organizations to quantify and report" independently how much waste they generate and determine the point of occurrence. "The Waste and Resource Action Program" (WRAP)
TABLE 1 | Edible and Inedible fractions (\%) of some perishable food items (Maletta and Maletta, 2012; Public Health England, 2015).

\begin{tabular}{lcc}
\hline Food types & Inedible fraction & Edible fraction \\
\hline Lime oranges & 36 & 37 \\
Peaches \& pears & 25 & 17 \\
Pineapples & 43 & 49 \\
Berries \& Quinces & 21 & 3 \\
Tangerine \& Asparagus & 60 & 70 \\
Artichokes & 66 & 57 \\
Cabbage & 16 & 22 \\
Carrot & 18 & 17 \\
Broccoli & 42 & 20 \\
Cucumber & 23 & 3 \\
Eggplant & 8 & 19 \\
\hline
\end{tabular}

proposed classification of waste into "totally-avoidable waste, probably-avoidable waste and non-avoidable waste" (WRAP, 2019). Totally-avoidable waste is defined as food commonly consumed, while probably-avoidable waste as food probably fit for human consumption such as peel and non-avoidable waste as food that is not fit for human consumption such as leaves. These three categories of waste were quantified using "non-avoidable waste intensity" (NWI), "totally-avoidable waste intensity" (TWI) and "Probably-avoidable waste intensity" (PWI) of a product. The NWI, TWI or PWI is defined as the ratio of the weight fraction of non-avoidable/totally-avoidable/probably avoidable waste to the total quantity of food purchased. These are shown on Equations (1-3), respectively, below:

$$
\begin{gathered}
\text { NWI }(\%)=\frac{\text { non }- \text { avoidable waste }[\mathrm{Mt}]}{\text { total purchases }[\mathrm{Mt}]} \\
\text { TWI }(\%)=\frac{\text { totally }- \text { avoidable waste }[\mathrm{Mt}]}{\text { total purchases }[\mathrm{Mt}]} \\
P W I(\%)=\frac{\text { Probably avoidable waste }[\mathrm{Mt}]}{\text { total purchases }[\mathrm{Mt}]}
\end{gathered}
$$

Whereby NWI, TWI, and PWI of Equations 1, 2, and 3 are the proportion of product that is wasted non-avoidably, totally-avoidably or probably-avoidably, respectively. The "total purchases" in each expression refers to total amount of food acquired. The NWI of food loss or waste is considered equal to the inedible fraction of the food. The varying amounts inedible fractions of food are presented in Table 1 for perishable food items. Some variables were taken into consideration for differences in the two sets of data. For example, determination of edible asparagus by Public Health England (2015) totally eliminate the base measuring the edible fraction and therefore of inedible fraction is quite lower in comparison with other data.

Characteristics of certain products have been linked the level of generation of avoidable/possibly avoidable wastes. The amount of time it takes for certain food item to perish or considered unfit for human consumption and the commodity price are contributing factors to the values of "totally avoidable" and 
"probably avoidable" waste intensity. This is based on the fact that the purchase of cheaper commodities might be higher than necessary and as consequence, some of the products are left to spoil in comparison to high end food items. Similarly, certain food prone to high degree of perishability are more likely to be left as waste if stored for long period of time or under abusive storage situation. The perishability of certain commodities is generally linked to its shelf life. The period of time a perishable product becomes "unsuitable for consumption during storage often refers to its shelf-life." Fishes, fresh fruits and nuts are composed of living cells throughout the supply chain up to when they are consumed and the shelf-life are dependent on storage conditions, ripening condition, time of harvest, conditions of growth, and type of packaging of products (Demirel, 2018). Classification of food waste either as totally-avoidable or nonavoidable is an indication of thorough perception of causes of FLW which invariably leads to probable development of appropriate prevention model, and capturing of totally-avoidable waste in the waste-flow analysis.

Definition of food waste in production chain is focused on the flow of food products that were originally designed for human consumption but diverted in the food supply chain (examples include slaughter, wholesale, packaging and retail) and rather were used as feedstocks or diverted for waste treatment facility. The "non-edible" parts of waste /loss such as orange peels and meat bones are not accounted for or deliberately omitted in the definition. FWL under this definition are captured as "side flows" (SF).

\section{Disposal Methods of Food Wastes}

The production of food loss and waste often lead large amount of wastewater and solid waste (Valta et al., 2017). These include food peels and seeds, residues from food membranes and non-edible parts of food. Wastewater on the other hand usually consists mainly of liquid waste constituting industrial effluents, wash liquor, cleaning liquid and other industrial solvent system. More often than not, the solid waste fractions are subjected to biological treatment (including anaerobic digestion), incineration, landfills, plowing in fields, dumping into the sea and open burning. Conventional practice ensures that the liquid waste is pretreated, and finally treated in stand-alone ponds in addition with municipal wastewater effluents (Nasr et al., 2014; Valta et al., 2015). Disposal of solid waste arising from food loss and waste have been carried out over time using several biological treatments, amongst which anaerobic digestion has proven to be highly cost-effective because of its inherent "high energy recovery," limited environmental impact and biogas production (Álvarez et al., 2010). The two-phase digestion system is particularly suitable for treating "solid wastes rich in solid matter and source-sorted organic waste of municipal solid wastes" associated with fruits and vegetable wastes such as potato peelings apple, green beans, green salad, and carrots. The process involves several hydrolytic liquefaction digesters for treating each type of solid food waste and ultimately linked to central methanogenetic fixed-bed reactor (Álvarez et al., 2010).

Sometimes, liquid wastes are first pretreated with solution of hydrogen peroxide to oxidize lower oxidation sate of sulfur and thereby adjusting the $\mathrm{pH}$ value to neutrality through addition of sodium hydroxide. Following this pre-treatment protocol, the solid biomass is ultimately degraded via oxidation using conventional biological treatment.

Disposal and treatment of food waste and loss via landfills or dumping sites for food waste and pre-treatment (including biological treatment) of waste liquids are not cost effective in addition to the introduction of toxic and harmful chemicals from wastewater treatment $\left(\mathrm{H}_{2} \mathrm{O}_{2}\right.$ and $\left.\mathrm{NaOH}\right)$ and $\mathrm{CO}_{2}$ releases into the environment. Alternative use of these organic biomass such as valorization into biofuel, bio-lubricant and other bioproducts is not only economically sound but environmentally compatible alternatives. These feedstocks from waste as source of biofuels and other bioproducts has possesses huge benefits in terms of savings from alternative use of land instead of landfill, electricity generation and savings in the cost of feedstocks for biofuel production.

Incineration of solid wastes arising from food is designed for combustible food waste which is suited in crowded cities where landfills and other disposal methods are not costeffective. It involves high construction and operational costs. The design includes primary chamber to facilitate rapid desiccation of moist food waste which typically involves the use of a ledge or drying hearth. The secondary chamber is operated at temperatures above $700^{\circ} \mathrm{C}$ for complete combustion of all unburnt or semi burnt wastes. This practice also is not only costly but unsustainable in terms of energy demand and environmental pollution.

\section{Environmental Impact of Current Disposal Methods}

The main driving force for the pursuit of alternative disposal of food loss and waste such as conversion to biofuels as a sustainable alternative is the total contribution of biomass to "climate change." The central theme of climate change hinged upon reduction of greenhouse gas (GHG) emission: gases that trap heat in the atmosphere. The major components of greenhouse gases include the following:

\section{Carbon Dioxide $\left(\mathrm{CO}_{2}\right)$}

This gas finds its way into the atmosphere through decomposition of biomass. The good news is $\mathrm{CO}_{2}$ can also be sequestered or absorbed by plants from the atmosphere during biological photosynthesis. In the United States (US), $\mathrm{CO}_{2}$ accounts for about $81.6 \%$ of the total greenhouse gases in 2016 (U.S. EPA, 2017). Some activities linked to humans are adversely affecting the "carbon cycle" by increasing atmospheric $\mathrm{CO}_{2}{ }^{\circ} \mathrm{r}$ by altering the effectiveness of natural carbon sinks, like forest to sequester carbon dioxide from the environment. The overall benefits of biofuels in $\mathrm{CO}_{2}$ reduction requires complete life cycle assessment data for comprehensive determination of natural resource requirements of biofuels and "environmental impacts from the life cycle" of biofuels. This requires a large amount of data and complete network of re-use, recycling, and eventual disposal information (The Royal Society, 2008). 


\section{Methane $\left(\mathrm{CH}_{4}\right)$}

It accounts for about $10 \%$ of total greenhouse gases. Main sources of methane emission include the manufacturing of coal, natural gas, fossil fuels, degradation of biomass in municipal waste and dumpsites and other related agricultural practices. The lifetime of methane in the environment is considerably shorter than $\mathrm{CO}_{2}$ due to its removal by natural chemical processes in soil and some other atmospheric chemical reactions. Nonetheless, methane is regarded to trap radiation more efficiently than $\mathrm{CO}_{2}$ that it is now considered as having greater comparative impact, that is, about " 25 times greater than $\mathrm{CO}_{2}$ over a 100 -year period" (U.S. EPA, 2017). In general, natural gas and fossil fuels are the largest contributors to $\mathrm{CH}_{4}$ emission.

\section{Nitrous Oxide $\left(\mathrm{N}_{2} \mathrm{O}\right)$}

The contribution of nitrous oxide to GHG emission in the US in 2016 was about $6 \%$. Major sources of $\mathrm{N}_{2} \mathrm{O}$ include human activities such as agriculture, fuel combustion, municipal waste management (from food loss and waste) and other industrial processes. $\mathrm{N}_{2} \mathrm{O}$ stays longer in the atmospheric environment "for $\sim 114$ years before it is eliminated either by sink or degraded through chemical processes" (U.S. EPA, 2017). Thus, comparatively, $\mathrm{N}_{2} \mathrm{O}$ impacts on global warming almost “300 times greater than carbon dioxide (IPCC, 2007). Agricultural practices such as application of fertilizer (synthetic or organic) and other farming activities" are highly implicated in $\mathrm{N}_{2} \mathrm{O}$ emission system. Contributions from industrial production of nitric acid and combustion of fossil fuels are also significant.

\section{Fluorinated Gases}

Some industrial processes emit "fluorinated hydrocarbons (HFCs), perfluorocarbons (PFCs), nitrogen trifluoride $\left(\mathrm{NF}_{3}\right)$ and sulfur hexafluoride $\left(\mathrm{SF}_{6}\right)$ " which are considered powerful greenhouse gases for their high global warming potential (GWPs). Fluorinated gases found their ways into the environment via several manufacturing processes including aluminum manufacturing and semi-conductor processing. They are considered as long lasting atmospheric global warming gases, lasting thousands of years in the atmosphere. Many fluorinated gases are difficult to remove from the atmosphere unless degraded by some photochemical reactions in the far upper atmosphere. The main source of fluorinated gases is their use as refrigerating gases in cooling systems in homes, offices and vehicles (US Energy Information Administration, 2013, 2018). They were designed as an alternative for chlorofluorocarbon and hydrochlorofluorocarbons which are now being replaced under the Montreal international agreement Protocol. The subsequent amendment Kigali to the Montreal agreement calls for reduction the manufacturing and application of the most harmful hydrofluorocarbons. This led to the recent development of hydrofluoroolefins (HFOs) which are characterized by "shorter lifetimes in the atmosphere and low global warming potentials." The relative contribution of these gases to the overall greenhouse gases are shown in Figure 1.

Strategies at minimizing and reduction of food loss and wastes can be viewed from two dimensions of potentially reducing GHG emissions of both regulated and unregulated pollutants and the

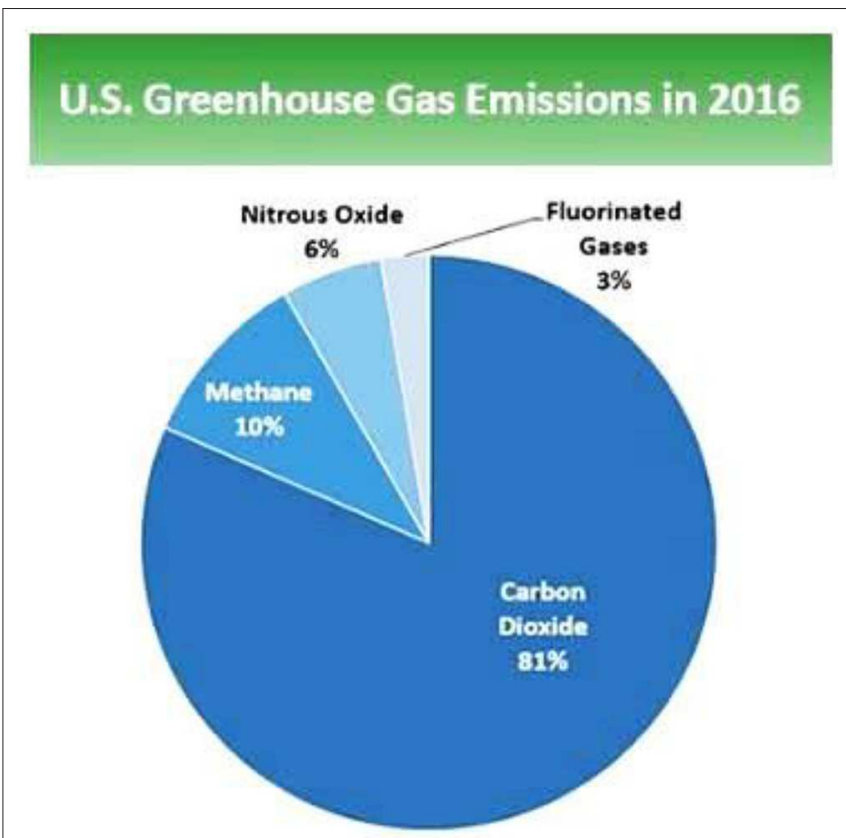

FIGURE 1 | Total greenhouse gas emission in 2016 (6,511 million metric tons) of $\mathrm{CO}_{2}$ equivalent (US Energy Information Administration, 2018).

opportunity to future developments of alternative use of food loss and waste. This include life cycle assessment (LCA) of the total environmental and health impacts.

At a glance, biofuels can be seen as easily degradable and presents minimal health hazard upon human exposure. However, research has shown that admixture of bioethanol to gasoline distort the natural attenuation of "benzene, toluene, ethylbenzene and xylene" (BTEX) in ground water and soil. There is a potential health risk when one is exposed to these BTEX chemicals (US Energy Information Administration, 2013, 2018).

Similarly, increased farming activities for crop-based biofuels production (corn- based ethanol) could lead to eutrophication with detrimental environmental impacts to the ecosystem and estuarine. The net $\mathrm{CO}_{2}$ emissions from converting large carbon sinks land for biofuels production is " $\sim 1.5$ gigatonnes of cabon per year (GtC/yr)" (Grace, 2004; Baker, 2007). Drainage and bush-burning are some contributing factors to the emission of $\mathrm{CCO}_{2}$ in largely carbon sink forest as observed in peatland in South East Asian. Such $\mathrm{CO}_{2}$ emissions from the soil globally is irrespective of the "cause of the land change to the cultivation of crops." Thus, the cause of increase in $\mathrm{CO}_{2}$ emission cannot be solely attributed to disposal of biomass content of food loss and waste.

Burning of biofuels results in the emission of increased atmospheric pollutants such as $\mathrm{CO}_{2}$ and other oxides of nitrogen and sulfur in addition to some harmful oxidative hydrocarbon compounds and volatile organic compounds (VOC). Some of these air pollutants increase with biofuels while other gas emission decrease with the use of biofuel that is related on the molecular architecture of the biofuel and feedstock. 
TABLE 2 | U.S. bioethanol imports from select countries in caribbean and central America $(\$ 1,000)$ (International Energy Agency, 2016).

\begin{tabular}{lccccccc}
\hline Country & $\mathbf{2 0 0 2}$ & $\mathbf{2 0 0 3}$ & $\mathbf{2 0 0 4}$ & $\mathbf{2 0 0 5}$ & $\mathbf{2 0 0 6}$ & $\mathbf{2 0 0 7}$ & $\mathbf{2 0 0 8}$ \\
\hline Brazil & 0 & 0 & 2,150 & 743 & 10,326 & 4,495 & 4,835 \\
Costa Rica & 286 & 350 & 605 & 795 & 855 & 1,056 & 872 \\
El Salvador & 107 & 184 & 136 & 564 & 917 & 1,745 & 1,667 \\
Jamaica & 690 & 936 & 871 & 864 & 1,590 & 1,790 & 2,351 \\
Trinidada \& & 0 & 0 & 0 & 238 & 590 & 1,017 & 1,559 \\
Tobago & & & & & & & \\
\hline Total & 1,083 & 1,450 & 3,807 & 3,214 & 15,555 & 10,148 & 12,610 \\
\hline
\end{tabular}

GHG emissions and associated pollutants including $\mathrm{CO}$ and oxide of nitrogen from biofuels production are not necessarily less than the emission from conventional fossil fuels from the perspective of comprehensive life cycle analysis. When a thorough look at the entire carbon life cycle including use of land is taken in addition to the emission of "less prevalent but more potent GHG," such as $\mathrm{N}_{2} \mathrm{O}$ are considered, the benefits of biofuels as emitting less GHG in earlier studies need to be reexamined. It is even truer when the total GHG emission is considered from combustion of fuel and at every phase of the life cycle of fuel including processing, transportation, and uses as feedstocks for herbicides and fertilizer as well as distribution of biofuels.

Developing alternative use of food loss and waste such as biofuel feedstocks has direct social impacts in the rural communities where the feedstocks are derived. Studies showed that conversion technologies are situated near the source of feedstock, and thereby creating jobs for rural dwellers as well as wealth distribution to rural communities through corporate social responsibilities and social equity (Demirel, 2018). Rural farmers in developing countries who are involved in farming activities are more likely to benefit from higher commodity prices and biofuel inspired development dynamics. There is a need however, to consider the plight of the urban poor who is likely to bear the hardship of increased agricultural food products, unless improvement in quality of life rises across the entire spectrum of the society as whole and sufficient value-addition attributable to biofuel is retained locally (The Royal Society, 2008; Demirel, 2018).

Current U.S. policy on bioethanol import is quite favorable to suppliers from Central American countries including the Caribbean under the "Central American Free Trade Agreement" (CAFTA). This policy has led to importation of up to $7 \%$ of US domestic bioethanol demand "without being subject to the usual tariff of \$0.54/gal." Table 2 shows fuel ethanol import from selected Caribbean and Central American countries between 2002 and 2008.

The socio-economic impact and local prosperity of Nampula (Mozambique) and Inhambane (Gaza) from the cultivation and supply chain of bioethanol derived Eucalyptus and Swithcgrass as showed there were positive improvements in all the regions with respect to economic viability, local prosperity, social well-being, food security and land rights (Wicke et al., 2015).

\section{VALORIZATION OF FOOD WASTES}

In the past, nearly all petrochemical feedstock for production of valuable chemicals and commodity products were based on fossil fuels such as alkanes (ethane and butane), olefins ("ethylene, propylene and 1,3-butadiene") and aromatics such as BTX which were largely considered platform chemicals. The world is currently experiencing geographical and feedstock shift of platform chemicals for valuable chemical production from fats, oils and greases (FOG) and organic matter comprising of "cellulosic, hemicelluloses, and lignin matter" which are the main composition of food loss and wastes across North America, Europe and Southeast Asia countries. Intensive research in the past few years in synthetic organic chemistry, improvement in catalysts development and biotechnological advancement have recognized the following compounds of plants and animal wastes as potential building blocks for valuable chemicals and consumer products:

- Fatty acids and triacyl glycerides

- Carboxylic acids (acetic, glycolic, oxalic,3-hydroxypropionic, fumaric, succinic, asperic, malic, butyric, levulinic, itaconic, glutamic, adipic, citric, and gluconic acids)

- Olefins (ethylene and unsaturated fatty acids)

- Alcohols (ethanol, glycerol, propane diols, 1,2,4-butane triol, 2,3-butane diol, 1- butanol and sorbitols)

- Enzyme and carboxylic acid production: protease, lipase, cellulose, phytase, amylase, lignisase, xylanase, L-glutaminase, citric acid, lactic acid, gallic acid and gibberellic acid

- Others such as sucrose, furfural, acetone, lysine, antibiotics, poly hydroxyalkanoates, poly gammaglutamate and aromas.

These chemicals and many more are derived primarily from plant and animal sources including fats and oils, cellulose hemicellulose and lignin. Industrial utilization of these feedstocks primarily used as human food and animal feed was slowed due to renewed efforts on renewable fuels (bioethanol and biodiesel) and recent food vs. fuel debate. With the development of second-generation feedstocks (advanced biofuels), it becomes more obvious that biomass can be sufficiently produced for industrial chemical production and renewable fuels "with little negative impact on the supply chain of food products for human consumption" for the ever-growing world population (Biermann et al., 2011). Application of solid-sate fermentation technology have opened another frontier of valuable chemicals, enzymes, antibiotics, surfactants and industrial aromas (Bhargav et al., 2008). Exploring valuable chemicals from biomass is in tandem with the concept of green chemistry which focuses on transforming conventional chemical reactions with the more environmentally benign industrial process. Anastas and Warner (1998) defined green chemistry as the "efficient utilization of renewable feedstocks from plant and animal sources, elimination of waste" and avoidance of "the use of harmful and/or toxic reagents in the production and use of chemical compounds." This led to the 12 principles of green or renewable chemistry:

1. Atom efficiency

2. Waste prevention 
3. minimize harmful and/or toxic reagents

4. Innocuous solvents

5. Safer product design

6. Energy efficiency

7. Use of renewable materials

8. Fewer synthetic route

9. Catalysis instead of stoichiometry

10. Biodegradable product design

11. Safer processes

12. Pollution prevention methodologies.

These principles focused on the development of new reaction mechanisms that is environmentally safe, promote health of general population, energy efficiency and increased product selectivity. This is considered more sustainable for the world's growing population and industrial utilization of chemical resources. The emphasis is on renewable raw materials (plant and animal sources) as the preferred platform chemicals for development of valuable chemicals and coproducts. The following sections provide discussions on some valuable chemicals and products derivable from fats and oils, lignin and cellulose/hemicellulose of food waste and loss.

\section{Feedstocks for Biofuel Production}

Biofuel can be defined as the energy (work, heat or electrical) derived from biomass and its refined products. Biofuel is classified as solid, liquid, and gaseous biofuels depending on the physical state of the biofuel in-use. These include; bioethanol, biodiesel, bio-kerosene, natural gas (syngas) etc. Biofuel has been used for human activities such as heating of living environment, cooking of food and lighting of our homes since the beginning of human civilization. About " 83 billion liters of fuel ethanol is produced annually from farm crops whilst biodiesel from plant and animal oil continue to rise estimated at present capacity of 21,463 million liters per annum" (Guo et al., 2015). It is projected that market growth of biofuels worldwide will be " 30\% of the global energy demand before 2050.” Gasoline and other form of energy from fossil reserves are still occupying a significant greater position in our sources of energy today, estimated at greaterthan $80 \%$ of the total global energy consumption (US Energy Information Administration, 2013; Guo et al., 2015).

However, fossil reserves are limited and are nonbiodegradable. The enormous amounts of GHG emission from fossil fuels is another major concern. This led most developed nations around the world invest heavily in research and development and appropriate technology for application of renewable sources of energy including biofuel and co-products in order to minimize the environmental consequences (IPCC, 2013). Ethanol production from food wastes could be utilized as alternative for fossil fuels to power automobiles engines.

Automobile vehicles traveling the roads worldwide are in millions and "consume nearly 930 million gallons of gasoline per day" (U.S. EIA, 2013). This level of consumption has necessitated some environmental and socioeconomic concerns. Another major concern at the present consumption level is that, "the reserve of fossil fuels will be seriously compromised in another 45 years" (US Energy Information Administration,
2013). Therefore, the need for renewable sources of energy cannot be over emphasized. There may be need to adjust existing fermentation processes in order to generate adequate bio-ethanol from lignocelluloses matter (advanced biofuels) as a separate feedstock for bio-ethanol from food crop.

Adjustment of anaerobic digestion technology of organic wastes is currently in place around the world for the production of syngas $\left(\mathrm{CH}_{4}+\mathrm{CO}_{2}\right)$ via the methanogenesis and acetogenesis pathway (Álvarez et al., 2010). This is highly valuable gaseous biofuel. Commercial biogas plants around the world include biogas plant for potato slurry in Belgium with capacity of 150,000 tons/year and co-digestion biogas plant in Voghera, Italy with annual capacity of 27,000 tons/year.

Some species of cellulase (thermostable sp.) were identified and capable of high cellulosic degradation action at $>70^{\circ} \mathrm{C}$. Application of such enzymes in cellulosic bioethanol production reduces the costs production costs. Similarly, some yeasts have been developed for ethanol fermentation at more efficient manner and effective processes for optimization and commercialization of this technology. Thermo-chemical process is another emerging production technology for bioethanol production from cellulose and lignin derived from food wastes. The waste from several food categories including crops, vegetables, and fruits can be pyrolyzed to produce gaseous biofuel (syngas) a mixture of $\mathrm{H}_{2}$ and $\mathrm{CO}$ ) which can be subjected to some microbial activities in a special fermenter to produce bio-ethanol of approximate $50 \%$ yield.

\section{Solid Biofuel}

Biofuel derived from agricultural practices, forest and solid wastes are referred to as solid biofuels. It includes forest debris, woods, coal and other woody materials. Several years Before the discovery and commercialization of gasoline and petrol diesel, woods from forest in the form of pellets or chips were the major sources of energy for home heating, food preparation and light generation. Solid biofuel from different sources including woody types and non-woody can easily be converted to fire (or heat energy) through thermal combustion of organo-carbon contents at high temperatures $\left(\sim 260^{\circ} \mathrm{C}\right)$ using atmospheric oxygen. In 2008, "organic matter from plants and animals became the feedstock of choice for renewable energy, generating around 1,200 million tons of oil equivalent."

Solid biomass are pre-treated to minimize handling costs, storage and transportation and impact improved combustion quality on the final product. Pretreatment methods are usually matched to the chosen combustion technology which can be broadly classified as compacting and heat drying. Compacting or briquetting is designed to improve bioenergy densification of biomass through reduction in the overall volume of the biomass. The compacting method depends on the source of solid biomass. For instance, the squeezing and stabilization of agricultural crop straw is different from compaction of wastepaper or saw dust. The higher the briquetting pressure the denser the fuel becomes (Demirel, 2018).

Sawdust briquettes are obtained experimentally during compacting with screw press and hydraulic piston. Final product 


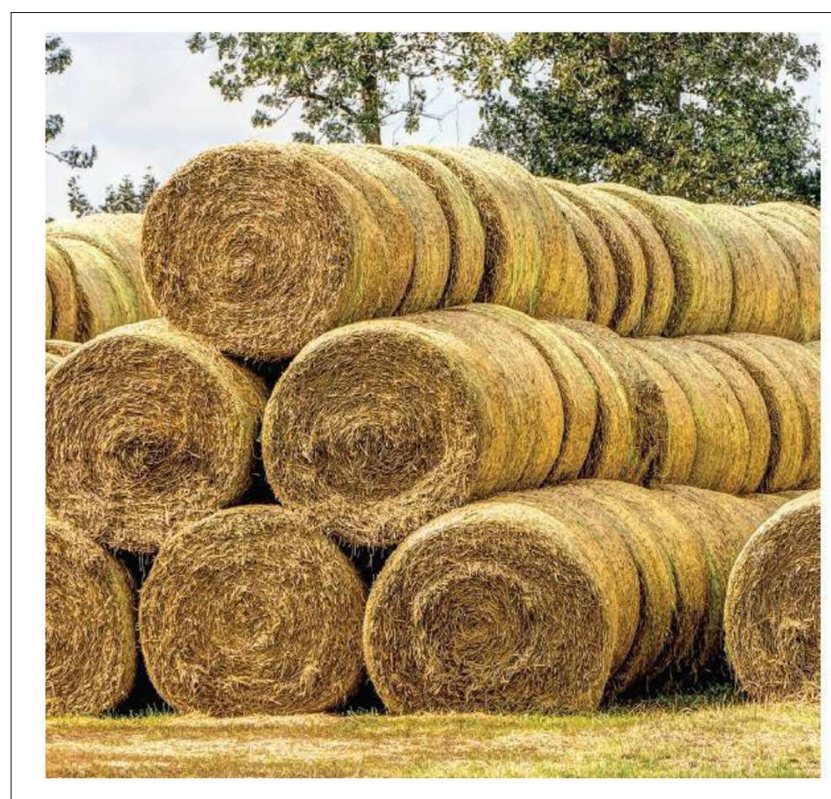

FIGURE 2 | Solid biofuel made from compacted crop straw (Royal Academy of Engineering, 2017).

density as high as $1,400 \mathrm{~kg} / \mathrm{m}^{3}$ and power of $22 \mathrm{kw}$ were obtained after compacting.

The energy density of woody material in general is nearly 15 $\mathrm{MJ} / \mathrm{kg}$ which is equivalent to one-half the energy content of fuels from fossil reserve (IPCC, 2013; Guo et al., 2015). Wood trims and chips from trees and branches have been used home heating and power generation. For instance, a boiler installed in Colgate University utilizing woodchips in Hamilton, NY provides about $75 \%$ of the heating and hot water requirements via the use of 20,000 tons of wood chips (Guo et al., 2015). Another variant of wood chips is Wood pellets, which is often referred to as refined wood chips. Wood pellets can generate nearly $18 \mathrm{MJ} \mathrm{m}^{-3}$ of energy. Biomass from FLW, and other agricultural wastes from food crops and trees can also be efficiently converted into wood chips and pellets or compacted as straw as shown on Figure 2.

Wood from mango plant was utilized to generate renewable energy (biofuel) in a typical fuel cell plant (Paul and Kumar, 2016). Other plant materials including orange plant, apple and coconut trees can be transformed to solid biofuels. The energy potential of these plant materials is as high as $19,100,000$ MJ/Square kilometer (Winzer et al., 2017). Woods from palm tree (including palm frond) have been reported as efficient feedstock for bioenergy. These solid biofuels are applied for home heating in the form of pellet stove. Some designs allow these stoves to be fed automatically for nearly $80 \%$ energy efficiency (U.S. DOE, 2013). The high energy potential of charcoal which is nearly $35 \%$ generates an estimated energy content as high as $28-33 \mathrm{MJ} \mathrm{kg}^{-1^{\prime \prime}}$.

Charcoal is renowned to undergo combustion "without generating flame and gaseous smokes at it high heating temperature of $\sim 2700^{\circ} \mathrm{C} "$ (Antal and Grønli, 2003). Global production per annum of charcoal is as high as 51 million tons (Van Gerpen, 2005).

\section{Liquid Biofuel}

The more predominant energy in the transport sector is liquid form of biofuels. These include bioethanol derived from fermentation, biodiesel from fats, oils and greases as well as renewable hydrocarbon fuels derived from plant and animal sources. The availability of renewable raw materials for bioethanol was first emphasized by Alexander Graham Bell in 1917 which described bioethanol as "any vegetable matter capable of fermentation, crop residues, grasses, farm waste, and city garbage." Bioethanol was experimented as an automobile fuel in 1913 well before the production and commercialization of petrol from fossil reserve. An American inventor named Samuel Morey, "designed and produced an internal combustion engine in 1826 that runs $100 \%$ on bioethanol". Total global production of bioethanol was 23.4 billion gallons in 2013, with contribution from US, Europe, Brazil, Canada and China at roughly $57,27,6,3$ and $2 \%$ respectively. The united states invested "114 million tons/year representing about $42 \%$ of its harvested grains from maize in bioethanol production to meet $10 \%$ blending gasoline fuel" (U.S. EIA, 2013). The exponential growth of biofuel production over the las decade with bioethanol contributing the vast majority of this growth which is produced predominantly in the US, Brazil and European Union (US Energy Information Administration, 2012; U.S. EIA, 2014). The world's largest producer of bioethanol is US which began in the early 1980 with a production capacity of $60 \%$ of the world production of 1,493,000 bpd in 2011 (Karatzos et al., 2014). The main driver of the US bioethanol production being energy security concerns arising from the fluctuation as well as rapid increases in petroleum prices in the 1970s.

Brazil, as the second largest bioethanol producer launched in 1975 in response to the increased oil prices of 1970s which was named "National Alcohol Program Protocol" designed to make Brazil independent of foreign oil imports and stabilize its growing sugarcane market. During this period the government of Brazil reached an agreement with automobile manufacturers whereby vehicles in Brazil ran on 100\% ethanol fuel in 1985.

The term biofuels' is commonly used for liquid biofuels which can be differentiated according to number of key characteristics. Typical characteristics employed include type of feedstocks, conversion technology, and technical specification of the biofuel as well as its end use. Classification according to type of feedstock is one common convention giving rise to the first, second and third generation biofuels (Royal Academy of Engineering, 2017) as shown on Table 3 which also showed alternative classification as 'conventional, ambiguous or advanced biofuels.

Biodiesel from plant and animal oil is equally important liquid biofuels derived from renewable feedstocks. Petro-diesel is a ' $\mathrm{C} 8^{-\mathrm{C}} 25$ ' fraction derived from fractional distillation of petroleum at $200-300^{\circ} \mathrm{C}$. Energy content of diesel in general is put at $\sim 38 \mathrm{MJ} \mathrm{L}^{-1^{\prime \prime}}$ which is higher than $34.7 \mathrm{MJ} \mathrm{L}{ }^{-1}$ energy content for gasoline. It is recommended for diesel engine transportation vehicles and agricultural vehicles and equipment including tractors, military vehicles, heavy construction vehicles and mining machineries. Other applications of diesel fuels include heating of homes, offices and industries as well as 
TABLE 3 | Classification of biofuels according to the type of feedstock, alternative classification and process technology (Royal Academy of Engineering, 2017).

\begin{tabular}{|c|c|c|c|c|}
\hline $\begin{array}{l}\text { Classification } \\
\text { (used in this } \\
\text { report) }\end{array}$ & $\begin{array}{l}\text { Alternative } \\
\text { classification }\end{array}$ & Feedstocks & Production & Products \\
\hline \multirow[t]{4}{*}{$\begin{array}{l}\text { First } \\
\text { generation }\end{array}$} & $\begin{array}{l}\text { Conventional } \\
\text { biofuels }\end{array}$ & Sugar crops & Transesterification & Bioethanol \\
\hline & & Starch crops & Fermentation & Biodiesel \\
\hline & & $\begin{array}{l}\text { Vegetable } \\
\text { oils }\end{array}$ & Hydrogenation & Methanol \\
\hline & & & $\begin{array}{l}\text { Fischer- } \\
\text { Tropsch }\end{array}$ & Butanol \\
\hline \multirow[t]{8}{*}{$\begin{array}{l}\text { Second } \\
\text { generation }\end{array}$} & Ambiguous & $\begin{array}{l}\text { Used } \\
\text { cooking oil }\end{array}$ & Gasification & $\begin{array}{l}\text { Mixed } \\
\text { alcohols }\end{array}$ \\
\hline & & Animal fats & Pyrolysis & Jet fuels \\
\hline & & Energy crops & Hydrolysis & $\begin{array}{l}\text { Vegetable } \\
\text { oil }\end{array}$ \\
\hline & $\begin{array}{l}\text { Advanced } \\
\text { biofuels }\end{array}$ & $\begin{array}{l}\text { Agricultural } \\
\text { residues }\end{array}$ & & \\
\hline & & $\begin{array}{l}\text { Forest } \\
\text { residues }\end{array}$ & & \\
\hline & & $\begin{array}{l}\text { Sawmill } \\
\text { residues }\end{array}$ & & \\
\hline & & $\begin{array}{l}\text { Wood } \\
\text { wastes }\end{array}$ & & \\
\hline & & $\begin{array}{l}\text { Municipal } \\
\text { solid wastes }\end{array}$ & & \\
\hline $\begin{array}{l}\text { Third } \\
\text { generation }\end{array}$ & & Algae & & \\
\hline
\end{tabular}

electricity generation (U.S. DOE, 2015). Biodiesel is designed to partially or completely replace fossil diesel arising from the shortfall and supply from petroleum sources. Biodiesel is a brownish-yellow liquid derived from plants and animal fats, oils and greases (Van Gerpen, 2005). Chemical composition of biodiesel is more or less mono-alkyl ester (usually fatty acid methyl ester). It is a "catalyzed trans-esterified product of fats, oils and greases" (FOG) and suitable alcohol. The fuel properties of biodiesel depend on the type of feedstock, alcohol and catalyst employed. It includes specific gravity range of $0.87-0.88$, lowest temperature of crystallization onset referred to as cloud point (CP) of $-4-14^{\circ} \mathrm{C}$, flash point (FP) range of $110-190^{\circ} \mathrm{C}$, external resistance to flow referred to as kinematic viscosity of $4.8 \mathrm{~mm}^{2}$ $\mathrm{s}^{-1}$, and centane number of 50-62. Its energy content $\sim 45 \mathrm{MJ}$ $\mathrm{kg}^{-1}$ which is nearly $90 \%$ of heating value of diesel derived from fossil reserve (Hoekman et al., 2012).

Pyrolysis bio-oil is also a liquid biofuel which is derived from high temperature $\left(300-900^{\circ} \mathrm{C}\right)$ pyrolysis of biomass in limited supply of air. Pyrolysis of plant biomass usually lead to three products namely the solid biochar, liquid bio-oil vapor condensate), and gas phase syngas. Almost any biomass may be used to generate bio-oil. Feedstocks include forest trees, crop residues, bagasse, peanuts debris, animal litters or switchgrass. Crude bio-oil is composed of over 300 chemical compounds such as char particulate matter and water molecules.

Other components of crude bio-oils include range of alcohols, carboxylic acids, carbonyl compounds, organic esters, carbohydrates, phenolic, unsaturated compounds, aromatics and nitrogen containing compounds. Unrefined bio-oil is usually unstable and corrosive product. It is highly viscous, insoluble in hydrocarbon fuel with minimal energy value and less flammable (Czernik and Bridgwater, 2004; Ringer et al., 2006; Junming et al., 2008; Vamvuka, 2011).

Refined bio-oil is a substitute for fuel oil either as biodiesel or heating fuel for static machineries including such as boilers, static engines, furnaces and electricity generation. Crude bio-oil is often used directly for heating purpose industrially using such techniques as atomization. In general, bio-oil is an important renewable feedstock for "platform chemicals, bio-lubricants, paints, binders, stabilizer, thickeners and preservatives".

Green biofuels, sometimes referred to as renewable biofuel is also a liquid biofuel with similar chemical and physical properties of existing gasoline. Research is ongoing to meet specifications of gasoline without damaging existing vehicle infrastructures and engines components at high blending ratios. Drop-in biofuel are often considered advanced biofuels or renewable diesel and gasoline derived from lipids and algae or cellulosic materials. They are similar in chemical structure to fossil fuel- based diesel and gasoline. These fuels do not have the compatibility issues with engines or vehicle infrastructure seen with biodiesel and bioethanol, making them ready to displace fossil- derived fuels in no distant future (Araújo et al., 2017).

The molecular oxygen contents of Bioethanol and biodiesel are higher than petrol fuels as well higher dissolution capabilities. When blended at rates $>20 \%$, often leads to damage of vehicle infrastructures including vehicle engines and elastomeric components (Araújo et al., 2017).

Suitable feedstocks for green biofuel include biomass, butanol., syngas complex and other suitable monosaccharides/disaccharides. Lignocellulosic sugars can be processed into gasoline using transition metal catalyst such as ruthenium for cyclization and dehydrogenation processes (Dowson et al., 2013; Duan et al., 2013). Research is in progress for commercialization of this process and also for appropriate redesign of existing ethanol plant for transformation to biobutanol. Drop-in biofuels have several advantages over conventional bioethanol or biodiesel. Amongst its superior performance includes its high hydrogen to carbon ratio, high carbon bond saturation and thus greater stability and low solubility in water. Specifically, it is associated with following advantages:

i High octane rating and thus, reduced ignition delayLow sulfur content and reduced sulfur oxide, nitrogen oxide and particulate matter emission

ii. Low aromatic content

iii. Absence of additives or oxygenates and thus, greater stability.

Renewable or drop-in biofuels are obtained from thermochemical, biochemical, hydro-treating and gasification processes. The thermochemical route involves controlled oxygen heating at high temperature, usually above $700^{\circ} \mathrm{C}$, whereby biomass is converted to liquid biofuels. Thermochemical process 
can be carried out as fast pyrolysis (short residence time), slow pyrolysis (long residence time) or under gasification at higher temperature and short residence time. Product spectrum from thermochemical conversion of biomass into drop in biofuel.

\section{Gaseous Biofuel}

Gaseous biofuel is another renewable fuel in gaseous state and considered as a replacement for natural gas or liquified natural gas (LPG). The energy value is estimated at $53 \mathrm{MJ} \mathrm{kg}^{-1}$ and composed mainly of methane gas at $\sim 95 \%$, followed by ethane gas estimated $5 \%$ and some trace amounts of propane, butane, nitrogen and carbon dioxide. LPG is used as cooking gas, heating, automobile fuels, electricity, and an important energy for industries. Sometimes referred to as biogas, produced by anaerobic degradation of organic biomass and other cellulosic materials. Biogas in its unrefined form is composed "of 65\% methane, $35 \% \mathrm{CO}_{2}$ and little amount of gaseous water, $\mathrm{H}_{2}$ and $\mathrm{H}_{2} \mathrm{~S}$ ". Usually $\mathrm{CO}_{2} \mathrm{H}_{2} \mathrm{~S}$ and other impurities are removed to generate biogas as renewable replacement of LPG (Niesner et al., 2013; Radu et al., 2017).

Synthesis gas or simply syngas is also another gaseous biofuel composed of $\mathrm{CO}, \mathrm{H}_{2}$ and $\mathrm{CO}_{2}$, from high temperature pyrolysis of organic matter. Unrefined syngas consists of about $47 \% \mathrm{~N}_{2}$, tar and some $\mathrm{H}_{2} \mathrm{~S}$. Application of syngas include generation of electricity and as a renewable feedstock (refined form) for the synthesis of automobile fuel and other valuable chemicals including methane (hydrocarbons) or alcohols such as ethanol or methanol and ether (Fischer-Tropsch process). Existing today are several syngas industrial gasification plants in several countries in the world. This include such commercial plants as 17, 56 and 42 syngas plants in US, China and Europe, respectively, in 2010 with a combined capacity of $71,205 \mathrm{MW}$ th. Although, roughly $0.5 \%$ of the syngas was derived from organic biomass, substantially greater proportion comes from coal, pet coke and LPG (Wang et al., 2009; del Alamo et al., 2012). Renewable energy generation from organic biomass via anaerobic digestion often include production of biogas. It is projected that biogas consumption is expected to reach $25 \%$ of present global LNG consumption if present process technology is optimized. An example of wood pyrolysis to syngas production and the accompanying chemical reactions were reported by Guo et al. (2015) with a "conversion rate of $\sim 92 \%$," that is, wood to $\mathrm{CO}, \mathrm{CO}_{2}$, and methane gas.

The thermochemical process (pyrolysis) converts biomass to char and vapor in the absence or limited amount of oxygen to generate a 'mixture of carbon dioxide and carbon monoxide, while the vapor is further pyrolyzed to carbon dioxide and water. Further combustion of char particulates results in the oxidative reaction with carbon dioxide to generate carbon monoxide, or by $\mathrm{H}_{2} \mathrm{O}$ leading to syngas (a mixture of carbon monoxide and hydrogen) as shown above. Syngas has an energy value of nearly $5 \mathrm{MJ} \mathrm{n} \mathrm{M}{ }^{-3 "}$ (Guo et al., 2015). And the fuel can be applied for electrical generation.

Biofuels can be synthesized and utilized in solid biofuel, liquid form or as gaseous fuels. However, specific applications is determined by several factors such as energy density, fuel efficiency and convenience. Solid biofuels in general are often applied at source and quite efficient in energy generation but low in energy density.
Thus, it is restricted to solid fuel burners. On the other hand, liquid biofuels are relatively denser in energy than solid biofuels and finds suitable applications as replacement for gasoline and petrol diesel in almost all stationary and automobile engines. Second generation (advanced) liquid biofuel have several advantages such as low combustion emissions, renewable and simple conversion technology. They are derived from organic biomass and waste which is considered positive environmental impacts. This is intended to mitigate the food vs. fuel debate the first-generation liquid biofuel generate.

Finally, gaseous biofuels is produced from a variety of feedstocks such as organic biomass and residues. Biogas "fits into the existing natural grid," while syngas can be produced existing mature production it also can serve as suitable feedstock for drop-in biofuel and other industrial chemicals.

\section{Renewable Source for Valuable Chemicals and Bio Refinery}

Due to sustainable' efforts on more environmentally friendly chemicals, we are witnessing both geographical and feedstock shift of platform chemicals for valuable chemical production from fats, oils and greases (FOG), cellulose, hemicellulose and lignin across North America, Europe and Southeast Asia countries. Research and development in organic chemistry, catalysis and biotechnology have contributed immensely in production of following valuable chemicals and compounds of plants and animal origin as potential building blocks for consumer products and development of bio refinery:

i. Fatty acids and triacyl glycerides from seed oils and nuts

ii. Carboxylic acids (acetic, glycolic, oxalic,3-hydroxypropionic, fumaric, succinic, asperic, malic, butyric, levulinic, itaconic, glutamic, adipic, citric, and gluconic acids) from biomass derived from plants

iii. Olefins (ethylene and unsaturated fatty acids) based on oleochemicals

iv. Alcohols (ethanol, glycerol, propane diols, 1,2,4-butane triol, 2,3-butane diol, 1 - butanol and sorbitols)

v. Others (sucrose, furfural, acetone, and lysine).

These chemicals and many more are derived primarily from plants and animals including fats and oils, cellulosic materials as well as hemicellulose and lignin (major components of food wastes and food loss). Industrial utilization of these feedstocks based on food wastes is an avenue for development of biorefinery and production of valuable chemicals and consumer products.

The chemical composition of fats, greases and oils are basically triglycerides of long fatty alkanes and/or alkenes attached to a glycerol backbone (triol). The main functional group remains the triglyceride ester, and most traditional and well-established chemical transformations of these molecules occurs mainly at the ester functional group.

Common chemical reactions of fats and oils include hydrolysis and esterification/transesterification to free acids, alkyl esters or more specifically, fatty acid methyl ester (FAME) which is present day biodiesel. Other common reactions include transformation of fatty acids at the carboxyl functional groups to detergents and soaps, amides, esters, acyl halides and fatty 


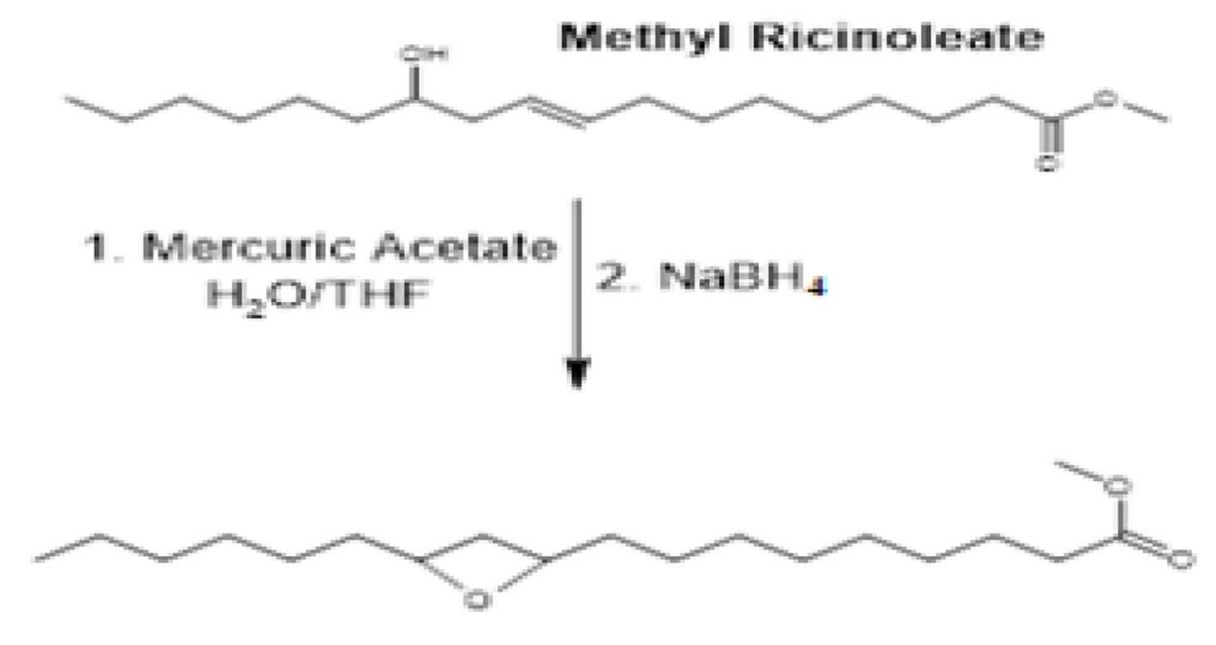

FIGURE 3 | Conversion of methyl recinoleate to cis-10,12epoxy-12-hydroxystearate and its rearrangement product, hydroxy 1,4-epoxides.

alcohols (Biermann et al., 2011). The basic platform chemicals based on fats and oils for transformation to valuable consumer products are:

i. Long chain carboxylic acids (52\%)

ii. Esters such as FAME (11\%)

iii. Long chain amines (9\%) and

iv. Fatty alcohols (25\%).

The chemical composition and distributions of these important functional groups abounds in fats and oils (Biermann et al., 2011). These renewable platform chemicals derived from fats and oils are used for production of soaps, surfactants, polyesters, polyamides, lubricants and coatings (Elvers et al., 2011). The production of " 1,2 and 1,3- propanediol, acrylic acid" and epichlorohydrins in large volume was based on glycerol byproduct of FAME production in recent years. This development is rapidly transforming the landscape of bulk chemical production from petrochemical industries to renewable raw materials. The presence of double bonds in some fats and oils allows increased reactivity such as hydrogenation, epoxidation, and oxidative cleavage. These platform chemicals based on fats and oils offer important synthetic applications that will be discussed in the following section.

Oxidation of diene to diacetate and triene can be achieved via anodic oxidation (Biermann et al., 2011). The triene is an important chemical for water resistant vanishes application.

Linoleic acid and conjugated linoleic acids (and their corresponding methyl esters) can simply be hydroxylated with selenium dioxide $\left(\mathrm{SeO}_{2}\right)$. While reaction with linoleic acid produce mono-hydroxylated derivatives, when $\mathrm{SeO}_{2}$ react with conjugated linoleic acids the dehydroxylated derivatives such as "12, 13-dihydroxy-10E-octadecenoic acid, 11,12-dihydroxy9E-octadecenoic acid and 10,11-dihydro-12E-octadecenoic acid" were produced (Li et al., 2009). These reactions using selenium dioxide were applied to introduce hydroxyl groups in the adjacent carbon to the unsaturated double bond positions in a one-step reaction process ( $\mathrm{Li}$ et al., 2009).
Abbot and Gunstone (1971) reported the conversions of longchain fatty acids and their corresponding esters to 1,4epoxides (2.5-disubstituted tetrahydrofurans via acid catalyzed cyclisation of polyhydroxy stearic acids. Other mechanisms include the free radical cyclisation of some hydroxyl esters, oxymercurationdemercuration, and epoxidation of some hydroxy stearates. Methyl ricinoleate, which is a $\beta$-hydroxy alkene reacts with m-chloroperbenzoic acid to yield "methyl cis-9,10-epoxy-12hydroxystearate" which readily rearranges upon treatment with boro trifluoride to give hydroxy 1, 4-epoxide as shown on Figure 3.

Several other important chemicals can be obtained from fatty acids. Chemical halogenation be can be carried out via chlorination, bromination and iodination using e.g., monochloride of methyl recinoleate furnish dihalides in addition to halogen-containing cyclic ether (Gunstone and Perera, 1973).

Food wastes are residues of agricultural crops including plants and animals and altogether are described as biomass which are composed primarily of lignin, cellulose and hemicellulose. These characteristics make food waste a superior and renewable source for valuable chemicals, energy and consumer products (Lucas, 2015).

Lignin is derived from plant material as an amorphous polymer acting as an essential glue and giving the plant its structural integrity and the only biomass based on aromatic units: methoxylated phenylpropane structures such as alcohol derivatives of coumaryl, sinapyl alcohol and coniferyl alcohol. The lignin encompasses the celluloses and hemicellulose fractions as a glue holding these units together. On the other hand, the cellulose is a linear polysaccharide consisting of 1,4 glycosidic linkages of D-glucopyronose monomers. The monomer units in plant biomass varies from 10,000 to 15,000 glucopyronose units. Hemicellulose on the other hand is the branched polymeric material of five different sugar units: xylose and arabinose (pentoses) and galactose, glucose and mannose (hexoses). Lignocellulosic food waste can be converted into valuable chemicals (Lucas, 2015). 
Effective conversion of these lignocellulosic food wastes into valuable chemicals include depolymerization of lignin, enzymatic and acid hydrolysis of cellulose. Platform chemicals from C2 to C6 compounds are readily accessible from the hexoses and pentoses components of cellulose and hemicellulose while a wide range of valuable aromatic compounds based on benzene, toluene and xylene can be derived from lignin motifs (Holladay et al., 2007).

\section{Platform Chemicals From Cellulose and Hemicellulose}

Cellulose and hemicellulose are potential sources of highly valuable chemical can be classified according to the number of carbon content in each molecule as follows:

C2: Acids (acetic, glycolic, oxalic), ethanol, ethylene.

C3: Acids (3-hydroxypropionic, lactic, propionic, acrylic), acetone glycerol, and propane diols.

C4: Acids (fumaric, succinic, asperic, malic, asperic, butyric), 1,2,4-butane triol, 1- butanol, acetoin, and 2,3-butane diol.

C5: Acids (levulinic, itaconic, glutamic), furfural, and sugars (Xylose and arabinose).

C6: Acids (adipic, citric, gluconic), sucrose, sorbitol, 5hydroxymethyl furfural, and lysine.

Selective depolymerization of lignin can furnish a variety of valuable chemicals that are difficult to make from conventional petrochemical routes in addition to other highly useful products (Holladay et al., 2007). Valorization of food wastes (biomass) for bio refinery is exploring the chemical energy stored in these plants and animal waste for the synthesis of valuable chemicals and biofuels in addition to electricity generation. The "National Renewable Energy Laboratory" (NREL) defined bio refinery as a system for efficient conversion of biomass processes in an integrated sequence to produce bioenergy and valuable chemicals. Thus, several chemicals and co-products could be derived from these food waste if properly channeled into bio refinery.

Valuable commodities and consumer products derivable from these products include antifreeze, thermoplastic fibers, contact lenses, adsorbents phenolic resin and flavoring agents amongst others. Commercial applications of lignin-based products are quite diverse but suffice to list following important uses (Holladay et al., 2007):

1. Lignosulfonate salts is used in cement and concrete industry to enhance plasticity and fluidity to concrete

2. Animal feeds as calcium and sodium salt molasses additives.

3. Provide desirable rheological; properties to oil wells.

4. Polyelectrolyte dispersant and wetting/emulsifying agent

5. Leather treatment agent to prevent rots.

6. Expanders and surface modification agent for lead batteries

7. Manufacture of inks, carbon black and dye pigments.

8. Oxoaminated as Nitrogen fertilizers.

Proper integration of these chemical conversion processes in a biorefinery is required by identifying synergies in individual unit operations. Most of the lignocellulosic components of biomass from fruits and vegetable wastes, cereals, grains and sugar cane is conveniently transformed into suitable chemical products and energy in a biorefinery (Martin and Crossmann, 2013).

Substantial progress in the development of industrial and consumer goods based from biorefineries includes broad based biolubricants base oils containing furan ring and branched chain alkanes from oleic acid, milkweed oil, cotton seed oil, canola oil ricinoleic acid from soybean bean. Chemical and enzymatic modification of these renewable materials have led to commercial production of renewable lubricant base oil, cold flow imoprover additives, "green diesel," surface active agents and rusty and corrosion inhibitors (Adhvaryu et al., 2000; Seo et al., 2012; Yasa et al., 2017; Dunn et al., 2019; Liu et al., 2019).

Biorefinery process pose special challenges including the need to optimize heat of reaction favorable to biological catalyst, deactivation of enzymes by chemical products of reaction (such as high concentration of alcohol and glycerol), requirements for high energy demand and water in distillation columns and the need to minimize overall environmental impacts.

\section{CONCLUSION}

Valorization of food wastes and losses through integrated biorefinery conversion to valuable chemicals, energy and consumer products is viable alternative both in terms of economics, sustainability social and environmental impacts. All these are not without important challenges that require systematic and advanced biorefinery process design and optimization to ensure that the chemical conversion processes are energy efficient, economically viable, and capable of employment generation for the rural communities and with minimum environmental impact. This require interdisciplinary approach involving experts in food processing technology including food scientists, chemical engineers, chemists, mechanical engineers and process engineers to find a suitable design with minimum cost and maximum benefit. Suitable R \& D in the near term medium/long term need to be put in place to find suitable catalytic production process for transformation of lignocellulosic biomass which are the main composition of food wastes.

\section{AUTHOR CONTRIBUTIONS}

SI: developed and organized the manuscript body. GO: supervised the writing, made corrections in every step of the manuscript design and development.

\section{FUNDING}

This project is partially funded by Sustainable Agriculture Research and Education (SARE) Grant GNE19-203 on Improvements to Quality-related Limitations to Market Growth of Biodiesel and Renewable Hydrocarbon Diesel Produced from Low-value Feedstocks and U.S. Department of Agriculture, National Institute of Food and Agriculture (USDA-NIFA) Grant 2017-38821-26439 on Multi-Institutional Student Experiential Learning with Outreach Training on Water, Climate, Food Security, and Sustainable Agriculture. 


\section{REFERENCES}

Abbot, G. G., and Gunstone, F. D. (1971). Fatty acids, Part 31. The formation of some substituted vic-epoxyoctadecanoates and their conversion to 1,4-epoxides and other compounds. Chem. Phys. Lipids J. 7, 290-302. doi: 10.1016/0009-3084(71)90007-7

Adhvaryu, A., Erhan, S. Z., Liu, Z. S., and Perez, J. M. (2000). Oxidation kinetics of oils derived from unmodified and genetically modified vegetables using PDSC and NMR spectroscopy. Thermochim Acta 364, 87-97. doi: 10.1016/S0040-6031(00)00626-2

Álvarez, P., Burken, J. G., Coan, J. D., De Oliveira, M. E., Dominguez-Faus, R., Gomez, D. E., et al. (2010). Fundamentals of a Sustainable US Biofuels Policy. Houston, TX: James A. Baker III Institute for Public Policy, Rice University Civil and Environmental Engineering. 134. Available online at: https://www. bakerinstitute.org/research/; https://scholarship.rice.edu/bitstream/handle/ 1911/91401/EF- pub-BioFuelsWhitePaper-010510.pdf? sequence $=1$

Anastas, P. T., and Warner, J. C. (1998). Green Chemistry: Theory and Practice, 1st Edn. New York, NY: Oxford University Press. 135.

Antal, M. J. Jr., and Grønli, M. (2003). The art, science, and technology of charcoal production. Ind. Eng. Chem. Res. 42, 1619-1640. doi: 10.1021/ie0207919

Araújo, K., Mahajan, D., Kerr, R., and da Silva, M. (2017). Global biofuels at the crossroads: an overview of technical, policy, and investment complexities in the sustainability of biofuel development. Agriculture. 7:32. doi: 10.3390 /agriculture7040032

Baker, D. F. (2007). Reassessing carbon sinks. Science 317, 1708-1709. doi: $10.1126 /$ science. 1144863

Barrett, J., Peters, G., Wiedmann, T., Scott, K., Lenzen, M., Roelich, K., et al. (2013). Consumption-based GHG emission accounting: a UK case study. J. Climate Policy 13, 451-470. doi: 10.1080/14693062.2013.788858

Bhargav, S., Panda, B. P., Ali, M., and Javed, S. (2008). Solid-state fermentation: an overview. Chem. Biochem. Eng. J. 22, 49-70.

Biermann, U., Bornscheuer, U., Meier, M. A. R., Metzger, J. O., and Schafer, H. J. (2011). Oils and fats as renewable raw materials in chemistry. Angew. Chem. Int. J. 50, 3854-3871. doi: 10.1002/anie.201002767

Corrado, S., Caldeira, C., Eriksson, M., Hanssen, O. J., Hauser, H. E., van Holsteijn, F., et al. (2019). Food waste accounting methodologies: challenges, opportunities, and further advancements. Global Food Security 20, 93-100. doi: 10.1016/j.gfs.2019.01.002

Czernik, S., and Bridgwater, A. V. (2004). Overview of applications of biomass fast pyrolysis oil. Energy Fuels 18, 590-598. doi: 10.1021/ef034067u

De Laurentiis, V., Corrado, S., and Sala, S. (2018). Quantifying household waste of fresh fruit and vegetables in the EU. Waste Manag. 77, 238-251. doi: 10.1016/j.wasman.2018.04.001

del Alamo, G., Hart, A., Grimshaw, A., and Lundstrøm, P. (2012). Characterization of syngas produced from MSW gasification at commercial-scale ENERGOS Plants. Waste Manag. 32, 1835-1842.

Demirel, Y. (2018). Biofuels. In: Comprehensive energy systems. (New York,NY: Elsevier) 875-908. doi: 10.1016/B978-0-12-809597-3.00125-5

Dowson, G. R. M., Haddow, M. F., Lee, J., Wingad, R. L., and Wass, D. F. (2013). Catalytic conversion of ethanol into an advanced biofuel: unprecedented selectivity for n-butanol. Angewwandte Chemie - International Edition 52, 9005-9008. doi: 10.1002/anie.201303723

Duan, P., Bai, X., Xu, Y., Zhang, A., Wang, F., Zhang, L., et al. (2013). Non-catalytic hydropyrolysis of microalgae to produce liquid biofuels. Bioresour. Technol. 136, 626-634. doi: 10.1016/j.biortech.2013.03.050

Dunn, R. O., Wyatt, V. T., Wagner, K., Ngo, H., and Hums, M. E. (2019). The effect of branched-chain fatty acid alkyl esters on the cold flow properties of biodiesel. J. Am. Oil Chem. Soc. 96, 805-823. doi: 10.1002/aocs. 12226

Elvers, B., et al. (2011). Ullmann's Encyclopedia of Industrial Chemistry, 7th Edn. Weinheim: Wiley-VCH, 706.

FAO (2011). Statistical Annual Crop Production Statistics. Rome: Food and Agriculture Organization of the United Nations.

FAO (2013). Mitigation of Food Waste: Societial Costs and Benefits. Rome: FAO.

Ghosh, P. R., Fawcett, D., Perera, D., Sharma, S. B., and Poinern, G. E. J. (2017.). Horticultural loss generated by wholesalers: a case study of the canning vale fruit and vegetable markets in Western Australia. Horticulturae 3:34. doi: 10.3390 /horticulturae 3020034
Grace, J. (2004). Understanding and managing the global carbon cycle. J. Ecol. 92, 189-202. doi: 10.1111/j.0022-0477.2004.00874.x

Gunstone, F. D., and Perera, B. S. (1973). Fatty acids, Part 41. The halogenation of some long-chain hydroxy alkenes with special reference to the possibility of neighboring group participation leading to cyclic ethers or lactones. Chem. Phys. Lipids J. 11, 43-65. doi: 10.1016/0009-3084(73)90051-0

Guo, M., Song, W., and Buhain, J. (2015). Bioenergy and biofuels: history, status, and perspective. Renewable Sustainable Energy Rev. 42, 712-725. doi: 10.1016/j.rser.2014.10.013

Gustavsson, J., Cederberg, C., Sonesson, U., van Otterdijk, R., and Meybeck, A. (2011). Global Food Losses and Food Waste: Extent, Causes and Pevention. Rome: FAO.

Hartikainen, H., Mogensen, L., Svanes, E., and Franke, U. (2018). Food waste quantification in primary production - the Nordic countries as a case study. Waste Manag. 71, 502-511. doi: 10.1016/j.wasman.2017.10.026

Hoekman, S. K., Broch, A., Robbins, C., Ceniceros, E., and Natarajan, M. (2012). Review of biodiesel composition, properties, and specifications. Renewable Sustainable Energy Rev. 16, 143-169. doi: 10.1016/j.rser.2011.07.143

Holladay, J. E., Bozell, J. J., White, J. F., and Johnson, D. (2007). Top Valuable Chemicals From Biomass. Volume 11-Results of Screening From Potential Candidates From Biorefinery Lignin. Oak Ridge TX: PNNL-16983 Pacific Northwest National laboratory, DOE. 79. Available online at: https://www.pnnl. gov/main/publications/external/technical_reports/PNNL-16983.pdf

International Energy Agency (2016). IEA - Report: International Journal of Renewable Energy Research (IJRER).

IPCC (2007). Climate Change 2007 Synthesis Report. Fourth Assesment Report, Inter-Governmental Panel on Climate Change.

IPCC (2013). The Physical Science Basis. Inter-Governmental Panel on Climate Change, 1-29. doi: 10.1017/СBO9781107415324

Isah, S., Akanbi, T. O., Wyatt, V., and Aryee, A. N. A. (2019). Fruit, Nut, Cereal, and Vegetable Waste Valorization to Produce Biofuel. John Wiley \& Sons Ltd. doi: 10.1002/9781119383956.ch30

Junming, X., Jianchun, J., Yunjuan, S., and Yanju, L. (2008). Bio-oil upgrading by means of ethyl ester production in reactive distillation to remove water and to improve storage and fuel characteristics. Biomass Bioenergy 32, 1056-1061.

Karatzos, S., McMillan, J. D., and Saddler, J. N. (2014). Summary of IEA Bioenergy Task 39 report: "The Potential and Challenges of Dropin Biofuels" A Report by IEA Bioenergy Task 39. IEA Bioenergy, 21. Available online at: http://task39.sites.olt.ubc.ca/files/2014/01/Task-39-dropin-biofuels-report-summary-FINAL-14-July-2014-ecopy.pdf

Li, Z., Tran, V. H., Duke, K. R., Ng, M. C. H., Yang, D., and Duke, C. C. (2009). Synthesis and biological activity of hydroxylated derivatives of linoleic acid and conjugated linoleic acids. Chem. Phys. Lipids J. 158, 39-45. doi: 10.1016/j.chemphyslip.2008.12.004

Liu, S., Josephson, T. R., Athaley, A., Chen, Q. P., Norton, A., Lerapetritou, M., et al. (2019). Renewable lubricants with tailored molecular architecture. AAAS Sci. Adv. 5, 1-8. doi: 10.1126/sciadv.aav5487

Lucas, N. (2015). Conversion of carbohydrate biomass to value added chemicals. (Ph.D. Dissertation), Savitribai Phule Pune University, India.

Maletta, H., and Maletta, E. (2012). Climate change, agriculture and food security in Latin America. Am. J. Agric. Econ. 94,1236-1237.

Martin, M., and Crossmann, I. E. (2013). Systematic synthesis of sustainable biorefineries: a review. J. Am. Chem. Soc. 52, 3044-3064. doi: 10.1021/ie2030213

Nasr, M., Elreedy, A., Abdel-Kader, A., Elbarki, W., and Moustafa, M. (2014). Environmental consideration of dairy wastewater treatment using hybrid sequencing batch reactor. Sustainable Environ. Res. 24, 449-456.

Niesner, J., Jecha, D., and Stehlík, P. (2013). State of art review in biogas upgrading technologies: state of art review in European region. Chem. Engin. Trans. 35, 517-522. doi: 10.3303/CET1335086

Paul, S., and Kumar, U. (2016). Study of enzymatic saccharification and fermentation of hydrolyzed mango wood to produce biofuel for electrochemical renewable energy in fuel cell. SCIREA J. Sci. Technol. Energy Sources 1, 39-59.

Public Health England (2015). Guidance: Composition of Foods Integrated Dataset (CoFID). McCance and Widdowson's 'Composition of Foods Integrated Dataset' on the Nutrient Content of the UK Food Supply. Available online at: https:// www.gov.uk/government/publications/composition-of-foods-integrateddataset-cofid 
Radu, T., Blanchard, R. E., and Wheatley, A. D. (2017). "Biogas for sustainable rural communities: case studies," in Sustainable Energy in Kazakhstan: Moving to Cleaner Energy in a Resource-Rich Country, 1st Edn., eds Y. Kalyuzhnova and R. Pomfret (New York, NY: Routlege, Taylor and Francis Group), 304. doi: $10.4324 / 9781315267302$

Ringer, M., Putsche, V., and Scahill, J. (2006). Large-Scale Pyrolysis Oil Production: A Technology Assessment and Economic Analysis. Technical Report, NREL/TP-510-37779. U.S. Department of Energy, Office of Energy Efficiency and Renewable Energy, National Renewable Energy Laboratory. doi: $10.2172 / 894989$

Royal Academy of Engineering (2017). Sustainability of liquid biofuels. Prince Phillips House, London. 2-96. https://www.raeng.org/uk/biofuels

Seo, M. H., Kim, K. R., and Oh, D. K. (2012). Production pf novel compound, 10,12,-dihydroxystearic acid from ricinoleic acid by an oleate hydratase from lysinibacillus fusiformis. Appl. Microbiol. Biotechnol. 97, 8987-8995. doi: 10.1007/s00253-0134728-x

Stenmarck, A., Jensen, C., Quested, T., and Moates, G. (2016). Estimates of European Food Waste Levels (Stockholm: EU Fusions. IVL Swedish Environmental Research Institute), 80. Available online at: https://www. eu-fusions.org/phocadownload/Publications/Estimates\%20of\%20European $\% 20$ food\%20waste\%20levels.pdf

The Royal Society (2008). Sustainable biofuels: prospects and challenges. Royal Society, London 1-90.

U.S. DOE (2013). US Energy Sector Vulnerabilities to Climate Change and Extreme Weather. United States Department of Energy, 1689-1699. Available online at: https://www.energy.gov/sites/prod/files/2013/07/f2/20130710-EnergySector-Vulnerabilities-Report.pdf

U.S. DOE (2015). Alternative Fuels Data Center. United States Department of Energy. Available online at: https://afdc.energy.gov/fuels/

U.S. EIA (2013). International Energy Outlook 2013. United States Energy Information Administration, 312. Available online at: https://www.eia.gov/ outlooks/ieo/pdf/0484(2013).pdf

U.S. EIA (2014). Annual Energy Review 2011. United States Energy Information Administration.

U.S. EPA (2017). Inventory of U.S. Greenhouse Gas Emissions and Sinks. United States Environmental Protection Agency. Available online at: https:// www.epa.gov/ghgemissions/inventory-us-greenhouse-gas-emissions-andsinks

US Energy Information Administration (2013). International Energy Outlook. Outlook 2013.

US Energy Information Administration (2018). Electric Power Monthly: With Data for May 2018. Independent Statistics \& Analysis,.

US Energy Information Administration (USEIA) (2012). Annual Energy Outlook. With Projections to 2035. Washington, DC: USEIA, Office of Integrated and International Energy Analysis, U.S. Department of Energy. 252. Available online at: www.eia.gov/forecasts/aeo; www.eia.gov/outlooks/aeo/pdf/ 0383(2012).pdf

Valta, K., Damala, P., Panaretou, V., Orli, E., Moustakas, K., and Loizidou, M. (2017). Review and assessment of waste and wastewater treatment from fruits and vegetables processing industries in Greece. Waste Biomass Valorization $8,1629-1648$.

Valta, K., Kosanovic, T., Malamis, D., Moustakas, K., and Loizidou, M. (2015). Overview of water usage and wastewater management in the food and beverage industry. Desalination Water Treat. 53, 3335-3347 doi: 10.1080/19443994.2014.934100

Vamvuka, D. (2011) Bio-oil, solid and gaseous biofuels from biomass pyrolysis processes-An overview. Intl. J. Energy Res. 35, 835-862. doi: 10.1002/er.1804

Van Gerpen, J. (2005). Fuel processing technology. Sci. Dir. 86, 1097-1107. doi: 10.1016/j.fuproc.2004.11.005

Wang, Z., Yang, J., Li, Z., and Xiang, Y. (2009). Syngas composition study. Front. Energy Power Engin. China 3, 369-372. doi: 10.1007/s11708-009-0044-7

Wicke, B., Van Der Hilst, F., Daioglou, V., Banse, M., Beringer, T., GerssenGondelach, S., et al. (2015). Model collaboration for the improved assessment of biomass supply, demand, and impacts. Gcb Bioenergy 7, 422-437. doi: $10.1111 /$ gcbb. 12176

Winzer, F., Kraska, T., Elsenberger, C., Kotter, T., and Pude, R. (2017). Biomass from fruit trees for combined energy and food production. Biomass Bioenergy 10, 279-286. Available online at: https://pubag.nal.usda.gov/catalog/5848749

WRAP (2019). The Food Waste Reduction Road Map. Progress Report, The Waste and Resources Action Programme, 29. Available online at: http://wrap.org.uk/ sites/files/wrap/Food-Waste-Reduction_Roadmap_Progress-Report-2019.pdf

Yasa, R.S., Cheguru, S., Krishnasamy, S. Korlipara, P.V., Rajak, A.K., and Penumarthy, V. (2017). Synthesis of 10-undecenoic acid based C22-dimer acid esters and their evaluation as potentiallubricant basestocks. Industrial Crops and Products Journal 103, 141-151.

Zhang, D. Q., Tan, S. K., and Gersberg, R. M. (2010). Municipal solid waste management in China: status, problems and challenges. J. Environ. Manag. 91, 1623-1633. doi: 10.1016/j.jenvman.2010.03.01

Conflict of Interest: The authors declare that the research was conducted in the absence of any commercial or financial relationships that could be construed as a potential conflict of interest.

Copyright (C) 2020 Isah and Ozbay. This is an open-access article distributed under the terms of the Creative Commons Attribution License (CC BY). The use, distribution or reproduction in other forums is permitted, provided the original author(s) and the copyright owner(s) are credited and that the original publication in this journal is cited, in accordance with accepted academic practice. No use, distribution or reproduction is permitted which does not comply with these terms. 